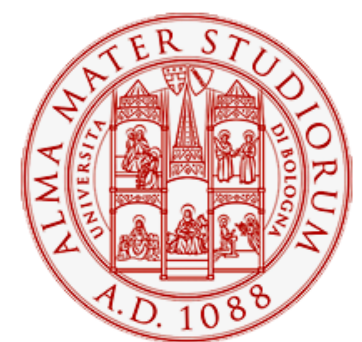

Alma Mater Studiorum - Università di Bologna DEPARTMENT OF ECONOMICS

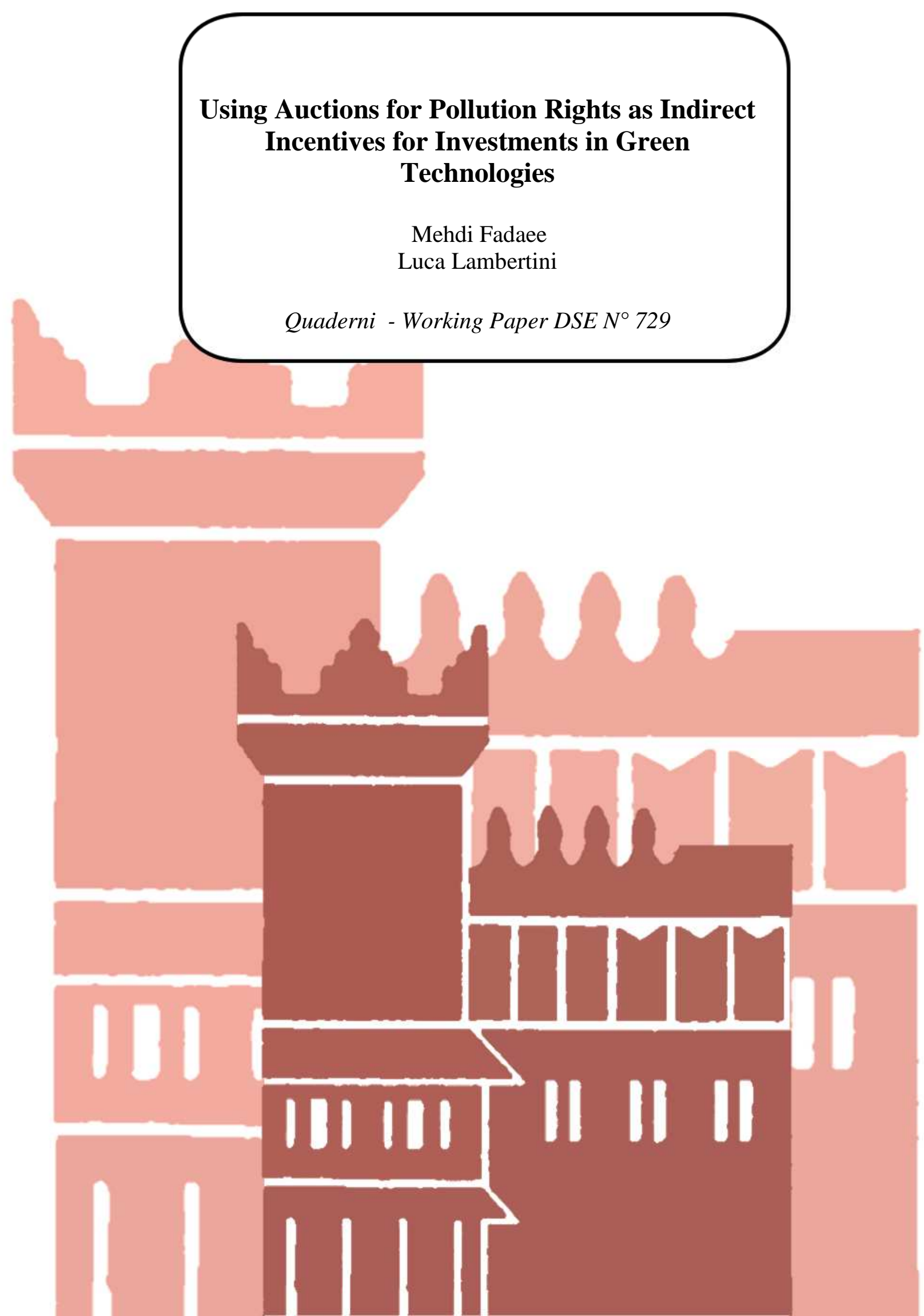




\title{
Using Auctions for Pollution Rights as Indirect Incentives for Investments in Green Technologies*
}

\author{
Mehdi Fadaee ${ }^{\dagger}$ Luca Lambertinit,\$ \\ $\dagger$ Department of Economics, University of Bologna \\ Strada Maggiore 45, 40125 Bologna, Italy \\ mehdi.fadaee2@unibo.it; luca.lambertini@unibo.it \\ fax +39-051-2092664 \\ $\S$ ENCORE, University of Amsterdam \\ Roetersstraat 11, WB1018 Amsterdam, The Netherlands
}

\begin{abstract}
Acquired wisdom has it that the allocation of pollution rights to firms hinders their willingness to undertake uncertain $R \& D$ projects for environmental-friendly technologies. We revisit this issue in a model where firms strategically choose whether to participate in an auction to attain pollution permits, or instead invest in green $\mathrm{R} \& \mathrm{D}$, to show that, somewhat counterintuitively, a side effect of the auction is in fact that of fostering environmental $R \& D$ in an admissible range of the model parameters. Keywords: environmental externalities, auctions, pollution rights, pollution-reducing innovation
\end{abstract}

JEL Classification: L13, Q55

${ }^{*}$ We thank Giacomo Calzolari for useful comments and suggestions on a previous draft. The usual disclaimer applies. 


\section{Introduction}

The regulation of industries producing negative environmental effects is a hot issue in the current literature. Most of the existing contributions in the field of environmental economics examine the existence of Pigouvian taxation aimed at inducing firms to reduce damaging emissions directly ${ }^{1}$ or indirectly ${ }^{2}$ (for an exhaustive overview, see Bovenberg and Goulder, 2002). Another possibility consists in assigning firms pollution rights, which in turn can be tradable. ${ }^{3}$ The latter, in general, is indeed a short run remedy that in principle does not modify the nature of the production technology used by firms, while clearly in the long run it would be best to attain new environmental-friendly technologies.

A compratively limited number of contributions investigate the link between some forms of environmental regulation and the incentives to generate and adopt green technologies or pollution-abatement measures (see Jung et al., 1996; Denicolò, 1999; and Scotchmer, 2010). In particular, Laffont and Tirole (1996) argue that pollution permits diminish or eliminate altogether firms' incentives towards green $R \& D$ because once a firm has acquired the right to pollute then she finds it more convenient to leave aside any uncertain and costly project eventually yielding a green technology.

Our aim is to nest into this debate by modelling the interplay between auctioning pollution rights on one side and the green innovation incentives on the other, so as to single out the possibility for a public agency aiming at preserving the environment to use the auction as an instrument to foster environmental R\&D. The mechanism yielding this result can be intuitively explained as follows. If the auction ends up in the assignement of pollution rights to a limited number of firms (say, one), the loosers face two alternatives: one is to stay out of the market, the other is to enter with a clean technology. In view of this, the regulator may set up the auction with this in mind, expecting to get two eggs in one basket. That is, awarding, say, monopolistic pollution rights to a single firm may not necessarily force the regulator to accept a suboptimal tradeoff between market power (and the associated negative price effect) and pollution abatement, if - with some positive probability - loosers are going to innovate and enter the market with new clean

\footnotetext{
${ }^{1}$ See Bergstrom et al. (1981), Karp and Livernois (1992, 1994), Benchekroun and Long (1998, 2002), Poyago-Theotoky (2007) and Tsur and Zemel (2008).

${ }^{2}$ To this regard, see Downing and White (1986), Milliman and Prince (1989), Damania (1996), Chiou and $\mathrm{Hu}$ (2001) and Tsur and Zemel (2002), Dragone et al. (2010).

${ }^{3}$ See von der Fehr (1993), Tietenberg (2003) and MacKenzie (2011), inter alia.
} 
technologies. To illustrate this perspective, we adopt a simple model involving two firms, that choose whether to participate in the auction or try their luck in uncertain $R \& D$ project aimed at the attainment of a green technology, and characterise (i) the equilibria of the game between firms, based on expected profit incentives, (ii) the consequences on consumer surplus, and (iii) the social preferences over alternative scenarios. The outcome of our analysis is that there exists a non-empty region of parameters where social and private incentives are indeed aligned, in such a way that at least one firm prefers to invest in $R \& D$, so that it appears that auctioning pollution rights can be taken - at least indirectly - as a means to drive profit-seeking firms to invest their resources in green technologies even in absence of taxation or subsidization.

The remainder of the paper is structured as follows. Section 2 illustrates the setup. Section 3 briefly outlines the problem from the consumers' viewpoint. In section 4 , the market equilibrium is illustrated. Section 5 assesses the social welfare consequences of market equilibria. An example based on the Cournot model is contained in section 6 . Section 7 concludes the paper.

\section{The setup}

Consider a one-shot game played by two single-product firms, indexed by $i=1,2$, supplying a homogeneous good with the same marginal cost. Initially, they share the same brown technology, whereby the production of the final output creates a negative externality in the form of polluting emissions. We suppose that, to mitigate the environmental implications of this technology, the government introduces a regulation according to which if a firm wants to produce she must not pollute the environment or she has to win the auction for pollution rights. Therefore, at the outset, each firm faces the following perspective:

- she can take part in the auction for emission rights; this involves a fixed fee $\epsilon>0$, in order to take part in the auction. The exogenous individual probability of winning the aution is $p=1 / 2$, and the winner must pay an additional cost, $F$, to the auctioneer for the permission to pollute the environment. Since $\epsilon$ and $F$ would be redistributed among consumers, the total effect of these costs on welfare is nought. The loser incurs a fixed cost $\Gamma$ to quit the market. Alternatively,

- the firm may invest a given amount, $K$, to attain a green technology which comes out 
of the $\mathrm{R} \& \mathrm{D}$ division with probability $\alpha \in[0,1]$. If so, she has the right to produce as her technology is now clean. If, instead, the $R \& D$ project yields no results, the firm incurs a fixed cost $\Gamma$ to quit the market. The innovation is patentable; in case both firms innovate, the authority allows both of them to patent the new technology and a symmetric green duopoly obtains.

In line with this setting, we have three cases: (i) both firms participate in the auction for pollution rights; (ii) both invest in R\&D looking for a green technology; (iii) one bids for pollution rights while the other invests in search of the green technology. In all cases, the marginal cost of production remains the same, the only difference between the two technologies is that one is clean and the other is not.

Therefore, denoting the participation in the auction as $\mathrm{A}$ and the search for a green technology as $\mathrm{G}$, we have the $2 \times 2$ game shown in matrix 1 .

2

\begin{tabular}{cc|c|c|}
\multicolumn{2}{c}{$\mathrm{A}$} & \multicolumn{2}{c}{$\mathrm{G}$} \\
\cline { 3 - 4 } 1 & $\mathrm{~A}$ & $E \pi^{A A}, E \pi^{A A}$ & $E \pi^{A G}, E \pi^{G A}$ \\
\cline { 3 - 4 } & $\mathrm{G}$ & $E \pi^{G A}, E \pi^{A G}$ & $E \pi^{G G}, E \pi^{G G}$ \\
\cline { 3 - 4 } & &
\end{tabular}

Matrix 1

Here, $E \pi^{G G}, E \pi^{G A}, E \pi^{A G}$ and $E \pi^{A A}$ are firms' expected profits when both invest in green technology, one of them invests in green technology and the other participates in the auction, or both take part in the auction, respectively.

Consider first the scenario where both firms are participating in the auction. In this case, the winner becomes a monopolist and makes monopoly profits, while the loser gets no revenues and also incurs a fixed cost $\Gamma$. Therefore, the individual expected profits in this case are:

$$
E \pi^{A A}=\frac{\pi_{M}-F-\Gamma}{2}-\epsilon
$$

where $\pi_{M}$ is gross monopoly profit.

Alternatively, when both firms invest in R\&D for a green technology, the expected profits for each firm are

$$
E \pi^{G G}=-K+\alpha\left[(1-\alpha) \pi_{M}+\alpha \pi_{D}\right]-(1-\alpha) \Gamma
$$


Expression (2) consists of the R\&D cost and the sum of (i) the monopoly profits if the firm succeed in innovation before the other because the innovation is patentable, and (ii) the gross duopoly profits, $\pi_{D}<\pi_{M}$, if both firms come out of the green technology at the same instant and get the new technology patented on parallel, as it is reasonable to imagine that a smart government would find it appealing to have two firms producing with the green technology at the same time.

In the third case, where one invests to attain a clean technology and one participates in the auction, since the firm which takes part in the auction is the only bidder, she wins the auction for sure and her expected payoff is

$$
E \pi^{A G}=-F+(1-\alpha) \pi_{M}+\alpha \pi_{D}-\epsilon
$$

which depends on whether the other succeeds in innovating or not. The probabilistic payoff for the firm activating the $R \& D$ project is

$$
E \pi^{G A}=-K+\alpha \pi_{D}-(1-\alpha) \Gamma .
$$

\section{The consumers' view point}

We shall now have a look at the level of consumer surplus generated by consumption (and therefore gross of the redistribution of $\epsilon$ and $F$ ) in the three different perspectives:

$(\mathbf{G}, \mathbf{G})$ In ths case, the expected surplus for consumers is the aggregate amount of the monopolistic consumer surplus when one innovates and the other one does not, and the duopolistic consumer surplus when both firms attain the innovation:

$$
E C S^{G G}=2 \alpha(1-\alpha) C S_{M}+\alpha^{2} C S_{D}
$$

where $C S_{M}$ and $C S_{D}$ are the levels of consumer surplus in monopoly and duopoly, respectively.

$(A, G)$ or $(G, A)$ If only one firm takes part in the auction while the other invests in $\mathrm{R} \& \mathrm{D}$, the expected consumer surplus becomes

$$
E C S^{A G}=E C S^{G A}=(1-\alpha) C S_{M}+\alpha C S_{D}-(1-\alpha) E_{M}-\alpha E_{D}
$$

illustrating the fact that depending on the probability of innovation, consumers incur some amount of negative externality either in monopoly, $E_{M}$, or in the asymmetric duopoly where only one of the two firms creates a negative externality, $E_{D}$. 


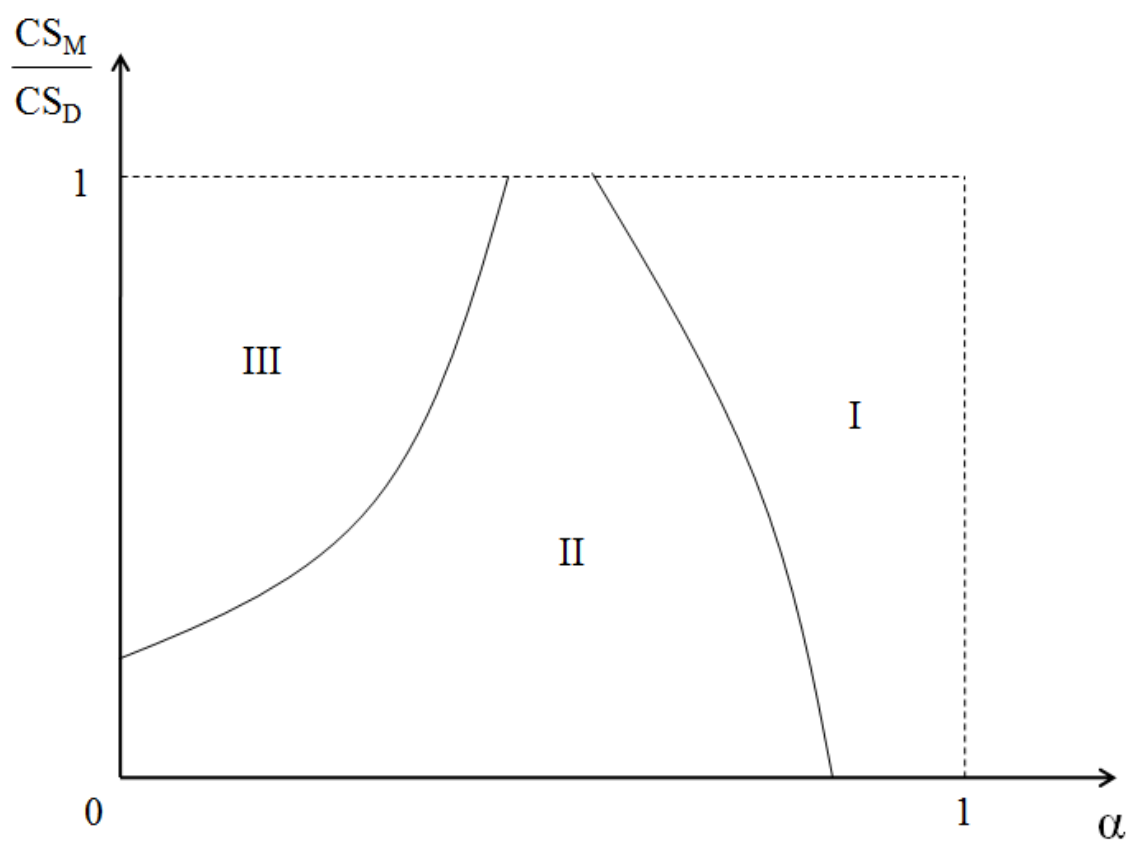

Figure 1: Consumer surplus comparison

$(\mathbf{A}, \mathbf{A})$ If both firms participate in the auction, one of them wins it and becomes a monopolist with the existing brown technology which obviously entails a negative externality for consumers:

$$
E C S^{A A}=C S_{M}-E_{M}
$$

By comparing these functions, since $C S_{D}>C S_{M}$ and $E_{M}>E_{D}$, it is easily shown that the expected amount of consumer surplus in the mixed case where one firm goes for the auction and the other goes for the green technology, $E C S^{A G}$, is always greater than $E C S^{A A}$.

Figure 2 spans the space $\left(\alpha, C S_{M} / C S_{D}\right)$ to describe consumer preferences over the three possible regimes. The curves results from $E C S^{G G}=E C S^{A G}$ (or equivalently $E C S^{G G}=$ $E C S^{G A}$ ) and $E C S^{A A}=E C S^{A G}$ (or equivalently $E C S^{A A}=E C S^{G A}$ ).

In region $I$, consumers prefer having both firms investing in a green technology, because in this area the probability of successful innovation is comparatively higher than elsewhere and therefore, it is very likely to have at least one firm achieving a green technology. Intuitively, this region expands as the amount of negative externality produced by the 
old technology increases. In regions $I I$ and $I I I$, consumers are better off when one of the two firms opts for the auction while the other invests in green R\&D. Moreover, in region $I I$ consumer surplus generated by $G G$ is greater than that associated with $A A$ while in region $I I I$ the opposite applies. As the negative externality created by the old technology increases, the border of these two regions shifts upwards and, as a result, region III shrinks.

Having ascertained that, from the consumers' standpoint, the presence of R\&D investment on the part of either firm is beneficial, there remains to assess the pivotal role of the $\mathrm{R} \& \mathrm{D} \operatorname{cost} K$ in determining whether there exists a parameter range wherein social and private incentives are indeed reciprocally aligned.

\section{Market equilibrium}

Here, we characterise the equilibrium of the game between the two firms. Their strategic behavour essentially depends on $\alpha$ as well as the difference between $F$ and $K$. Our analysis yields the following result:

Proposition 1 There exists a range of parameters in which the two firms play a chicken game in which $(G, A)$ and $(A, G)$ are Nash equilibria, with $E \pi^{G A}>E \pi^{A A}$ and $E \pi^{A G}>$ $E \pi^{G G}$.

Proof. By comparing (1), (2), (3) and (4), we have these three inequalities:

$$
\begin{gathered}
E \pi^{G G}>E \pi^{A G} \quad \text { if } \quad K<F-(1-\alpha)^{2} \pi_{M}-\alpha(1-\alpha) \pi_{D}-(1-\alpha) \Gamma+\epsilon, \\
E \pi^{G A}>E \pi^{A A} \quad \text { if } \quad K<\frac{1}{2}\left(F-\pi_{M}\right)+\alpha \pi_{D}-\left(\frac{1}{2}-\alpha\right) \Gamma+\epsilon, \\
E \pi^{G G}>E \pi^{A A} \quad \text { if } K<\frac{1}{2} F-\left(\frac{1}{2}-\alpha(1-\alpha)\right) \pi_{M}+\alpha^{2} \pi_{D}-\left(\frac{1}{2}-\alpha\right) \Gamma+\epsilon .
\end{gathered}
$$

If all the three inequalities hold, innovating a green technology is dominant strategy for both firms and $\left(E \pi^{G G}, E \pi^{G G}\right)$ will be the Pareto efficient equilibrium of the game. This equilibrium will not be Pareto efficient provided that the first two inequalities hold and the third one does not hold. If the first inequality does not hold and the second one holds, we have asymmetric equilibria in chicken game where one goes to the auction and the other invest in green technology. 


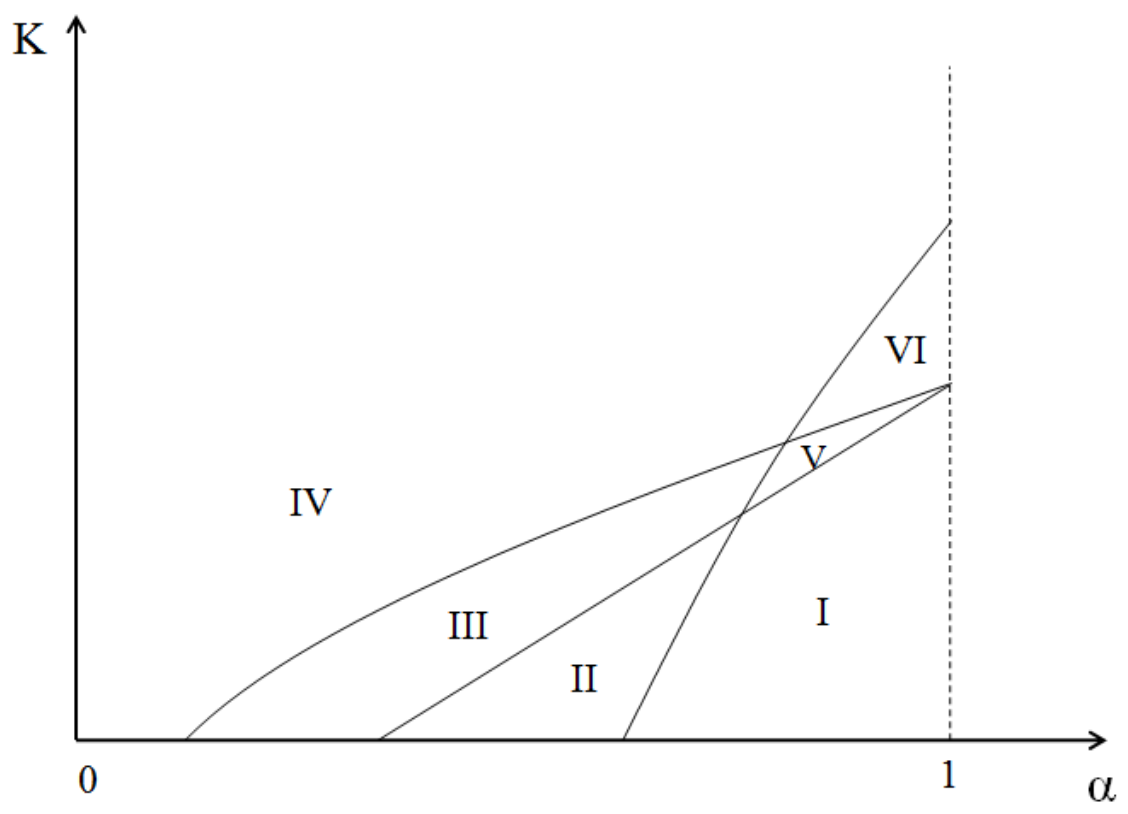

Figure 2: Profit comparison

In figure 2, the sub-regions of parameters $\alpha$ and $K$ for which each of the above inequalities is satisfied are represented by means of three dividing curves which are derived from (8), (9) and (10). ${ }^{4}$ In area $I,\left(E \pi^{G G}, E \pi^{G G}\right)$ is the unique and Pareto-efficient equilibrium. In region $I I$, matrix 1 becomes instead a chicken game in which one firm chooses to participate in the auction (and wins it) while the other goes for the green technology. In regions $I I I$ and $I V,\left(E \pi^{A A}, E \pi^{A A}\right)$ is the unique equilibrium. But while in $I V$, this equilibrium is Pareto-efficient, in $I I I$ the game reproduces a prisoner's dilemma. Regions $V$ and $V I$ gathers the points where the matrix becomes a coordination game with the two equilibria on the main diagonal of matrix 1, i.e., either both firms participate in the auction or both invest in search of the green technology. In $V, E \pi^{G G}>E \pi^{A A}$, while in $V I, E \pi^{A A}>E \pi^{G G}$.

\footnotetext{
${ }^{4}$ This exercise is carried out taking as given $\pi_{M}, \pi_{D}, \Gamma$ and $F$, that do modify the position and slope of the curves but leave unaffected the qualitative properties of figure 2 and therefore also the validity of out result.
} 


\section{Social optimum}

We are now in a position to put together consumers' likings and firms' incentives so as to evaluate social preferences according to the expected welfare levels arising in the three possible cases.

Since the auction fees are going to be redistributed across consumers, the social planner decides only on the basis of $K$ (and not $F$ ). Then, the expected amount of social welfare in each case is as follows:

$$
\begin{gathered}
E S W^{G G}=-2 K+2 \alpha(1-\alpha) S W_{M}+\alpha^{2} S W_{D}, \\
E S W^{A G}=E S W^{G A}=-K+(1-\alpha) S W_{M}+\alpha S W_{D}-(1-\alpha) E_{M}-\alpha E_{D}, \\
E S W^{A A}=S W_{M}-E_{M} .
\end{gathered}
$$

in which $S W_{M}$ and $S W_{D}$ are the social welfare levels (gross of external effects) in monopoly and duopoly, respectively.

By comparing (11), (12), (13) and knowing that $S W_{D}>S W_{M}$, we can characterise social preferences in the space $(\alpha, K)$ as in figure 3 .

This figure shows that social welfare is highest in $G G, A G$ (or $G A)$ and $A A$ if $(\alpha, K)$ are such that the industry allocation falls in region $I, I I$ and $I I I$, respectively.

Now, we have to ascertain whether the regions in figure 3 overlap, at least to some extent, with the corresponding regions in figure 2. More precisely, we are looking for conditions ensuring that the two regions labelled as $I I$ in figures 2 and 3 do overlap.

Proposition 2 There exists a range of parameters wherein profit incentives yield asymmetric equilibria generated by a chicken game where $E \pi^{G A}>E \pi^{A A}$ and $E \pi^{A G}>E \pi^{G G}$ and such equilibria are also socially efficient.

Proof. In order to prove the validity of this claim, it sufficies to observe that there are infinitely many admissible values of $F$ such that the curves delimiting region $I I$ in figure 2 intersect the horizontal axis in figure 3 between the origin and the curve dividing regions $I$ and $I I$ in figure 3 .

For illustrative purposes, in the next section we lay out an example based on the linear Cournot model. 


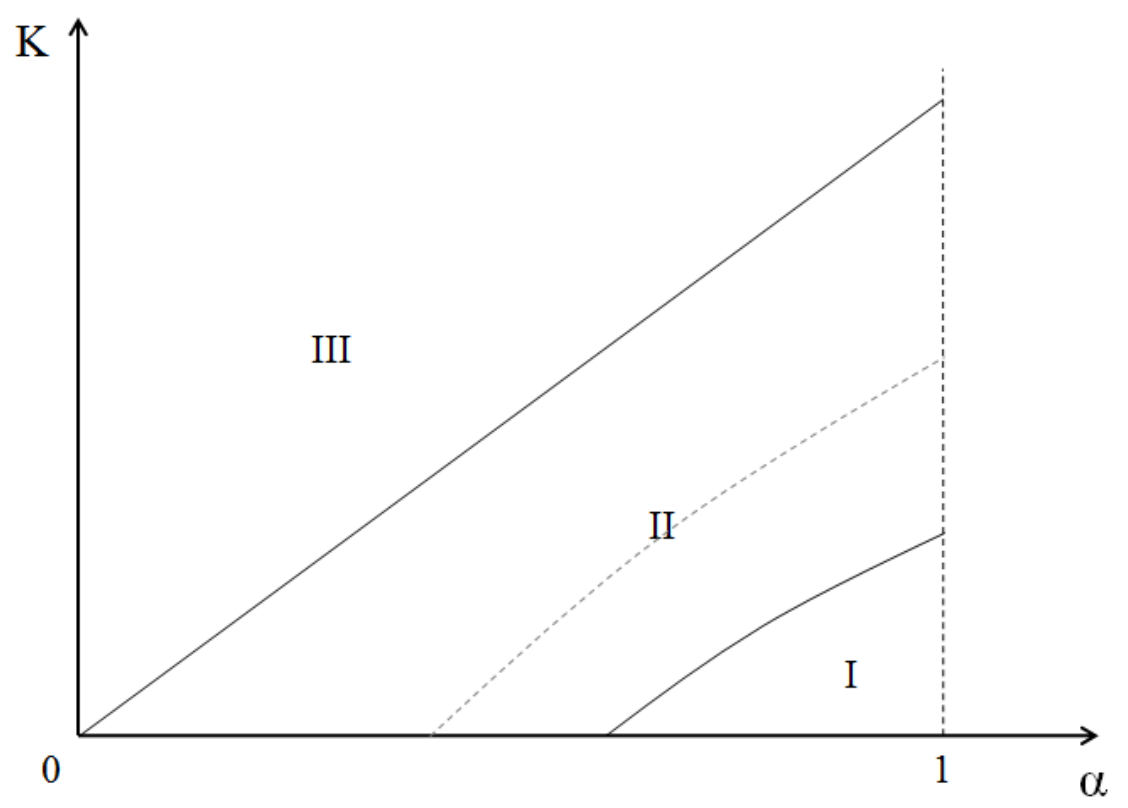

Figure 3: The solid line characterizes the points where expected social welfares in $A A$ and $A G(G A)$ are equivalent. On the dashed line $G G$ and $A G(G A)$ are the same, and on the dotted line $G G$ and $A A$.

\section{Example}

Consider a market where 2 symmetric firms producing the same homogeneous good with zero marginal cost $c=0$. The inverse demand function is defined as $p=A-Q$, where $Q=\sum q_{i}, i=1,2$ and $q_{i} \geq 0$ is the individual output of firm $i$. If firm $i$ wins the auction or invents a green technology, $q_{i}$ is strictly positive; otherwise she is not allowed to operate in the market. Accordingly, the industry can be either a monopoly or a duopoly. Therefore, the optimal level of output as well as the corresponding profits are either $q_{M}=A / 2$, $\pi_{M}=A^{2} / 4$ or $q_{D}=A / 3$ and $\pi_{D}=A^{2} / 9$, and the resulting social welfare levels (gross of negative externalities) are $S W_{M}=3 A^{2} / 8$ and $S W_{D}=4 A^{2} / 9$. To model pollution, we assume that the negative externality is a quadratic function of output, $E=b Q^{2} / 2$. Hence, externalities in the two cases are $E_{M}=b A^{2} / 8$ and $E_{D}=b A^{2} / 18$.

Then, plugging profits, social welfare levels and externalities in inequalities (8), (9) and (10), we get

$$
E \pi^{G G}>E \pi^{A G} \quad \text { if } \quad k<f-\frac{(1-\alpha)(9-5 \alpha)}{36}-(1-\alpha) \gamma
$$




$$
\begin{gathered}
E \pi^{G A}>E \pi^{A A} \quad \text { if } \quad k<\frac{f}{2}-\frac{(9-8 \alpha)}{72}-\left(\frac{1}{2}-\alpha\right) \gamma, \\
E \pi^{G G}>E \pi^{A A} \quad \text { if } \quad k<\frac{f}{2}-\frac{\left(10 \alpha^{2}-18 \alpha+9\right)}{72}-\left(\frac{1}{2}-\alpha\right) \gamma,
\end{gathered}
$$

where $k=K / A^{2}, f=F / A^{2}$ and $\gamma=\Gamma / A^{2}$. Here, for the sake of simplicity, we normalize $\epsilon$ to zero.

Note that in order for firms to have an incentive to take part in the auction, $F$ must not be greater than $\pi_{D}$, i.e. $f \leq \frac{1}{9}$, as the participant in the auction may expect the other firm to come up with new technology.

By comparing (11), (12) and (13) we find

$$
\begin{gathered}
E S W^{G G}>E S W^{A G} \text { if } k<\frac{b(9-5 \alpha)-(1-\alpha)(27-22 \alpha)}{72}, \\
E S W^{G A}>E S W^{A A} \text { if } k<\frac{5 \alpha(1+b)}{72}, \\
E S W^{G G}>E S W^{A A} \text { if } k<\frac{9 b+54 \alpha-22 \alpha^{2}-27}{72} .
\end{gathered}
$$

Now, we can perform a numerical simulations by normalizing all but two parameters. For instance, taking plausible values $b=\frac{1}{2}, f=\frac{1}{10}$ and $\gamma=\frac{1}{5}$, we can plot $k$ against $\alpha$ to assess inequalities (14), (15), (16), (17), (18) and (19). The outcome is illustrated in figure 4.

In regions $I, I I$ and $I I I$, firms and the social planner alike prefer $G G, A G(G A)$ and $A A$, respectively. Therefore, it can be seen that there indeed exists a viable range of parameters (area $I I$ ) where we have a chicken game whose equilibria are also welcome from the planner's viewpoint. This confirms our main point that using the instrument of auctioning pollution rights may serve the purpose of creating a side incentive for firms losing the auction in the first place or deciding not to participate in the auction to take the alternative root which is to finance $R \& D$ efforts for green technologies.

\section{Concluding Remarks}

There are two main lines of research in modelling the abatement of polluting emissions: the optimal assignment of pollution rights and the introduction of corrective taxes or subsidies to internalize the externality and provide firms with R\&D incentives that otherwise would not arise spontaneously. 


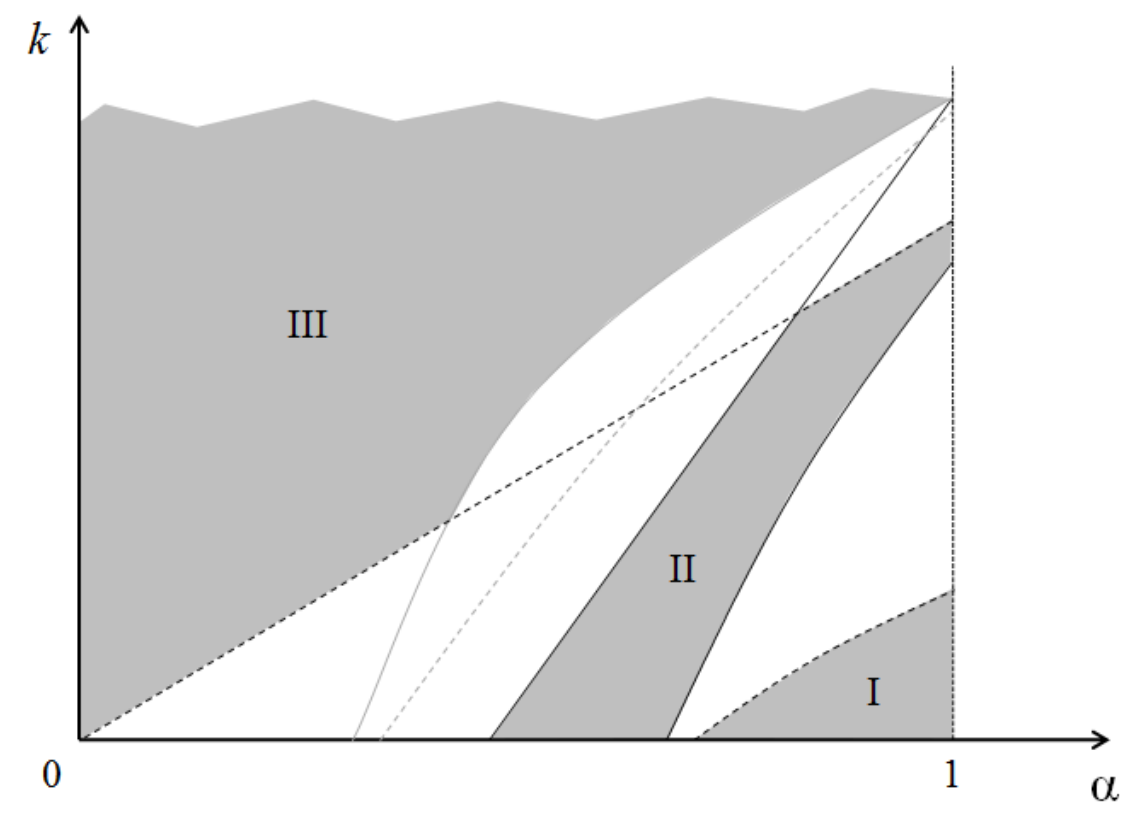

Figure 4: The regions where firms' equilibrium and welfare optimum coincide. Solid lines perform the firms conditions and dashed line perform the welfare conditions. The grey lines represent the borders between $G G$ and $A A$.

We have taken an alternative route to highlight the possibility that auctioning pollution rights might actually turn the loosers into green innovators. According to our analysis, it seems indeed that auctions may exert - somewhat unexpectedly - some positive long-run impacts on the environmental performance of industries by virtue of indirect innovation incentives that can be considered as the side-effect of the allocation of pollution rights. 


\section{References}

[1] Benchekroun, H. and N.V. Long (1998). Efficiency inducing taxation for polluting oligopolists. Journal of Public Economics, 70, 325-42.

[2] Benchekroun, H. and N.V. Long (2002). On the multiplicity of efficiencyinducing tax rules. Economics Letters, 76, 331-36.

[3] Bergstrom T.C, J.G. Cross and R.C. Porter (1981). Efficiency-Inducing Taxation for a Monopolistically Supplied Depletable Resource, Journal of Public Economics, 15, 23-32.

[4] Bovenberg, A.L. and L.H. Goulder (2002), Environmental Taxation and Regulation, in A.J. Auerbach and M. Feldstein (eds), Handbook of Public Economics, vol. 3, 1471-1545.

[5] Chiou, J.-R. and J.-L. Hu (2001). Environmental research joint ventures under emission taxes. Environmental and Resource Economics, 21, 129-46.

[6] Damania, D. (1996). Pollution taxes and pollution abatement in an oligopoly supergame. Journal of Environmental Economics and Management, 30, 323-36.

[7] Denicolò, V. (1999). Pollution-reducing innovations under taxes or permits. Oxford Economic Papers, 51, 184-199.

[8] Downing, P.B. and L.J. White (1986). Innovation in pollution control. Journal of Environmental Economics and Management, 8, 225-71.

[9] Dragone, D., L. Lambertini, G. Leitmann and A. Palestini (2010). A Stochastic Optimal Control Model of Pollution Abatement. Nonlinear Dynamics and System Theory, $10,117-24$.

[10] Jung, C., K. Krutilla and R. Boyd (1996). Incentives for advanced pollution abatement technology at the industry level: An evaluation of policy alternatives. Journal of Environmental Economics and Management, 30, 95-111.

[11] Karp, L. and J. Livernois (1992). On efficiency-inducing taxation for a non-renewable resource monopolist. Journal of Public Economics, 49, (2), 219-39.

[12] Karp, L. and J. Livernois (1994). Using automatic tax changes to control pollution emissions. Journal of Environmental Economics and Management, 27, 38-48.

[13] Laffont, J.-J. and J. Tirole (1996). Pollution permits and environmental innovation. Journal of Public Economics, 62, 127-140.

[14] MacKenzie, I.A. (2011). Tradable permit allocations and sequential choice. Resource and Energy Economics, 33, 268-78.

[15] Milliman, S.R. and R. Prince (1989). Firm incentives to promote technological change in pollution control. Journal of Environmental Economics and Management, 17, 24765. 
[16] Poyago-Theotoky, J. (2007). The organization of R\&D and environmental

[17] policy. Journal of Economic Behaviour and Organization, 62, 63-75.

[18] Scotchmer, S. (2010). Cap-and-trade, Emissions taxes, and innovation. Mimeo, Department of Economics, University of California, Berkeley.

[19] Tietenberg, T. (2003), The tradable-permits approach to protecting the commons: lessons for climate change. Oxford Review of Economic Policy, 19, 400-19.

[20] Tsur, Y. and A. Zemel (2002). The regulation of environmental innovations. Journal of Environmental Economics and Management, 44, 242-60.

[21] Tsur, Y. and A. Zemel (2008). Regulating environmental threats. Environmental and Resource Economics, 39, 297-310.

[22] von der Fehr, N.-H.M. (1993). Tradable emission rights and strategic interaction. Environmental and Resource Economics, 3, 129-51. 


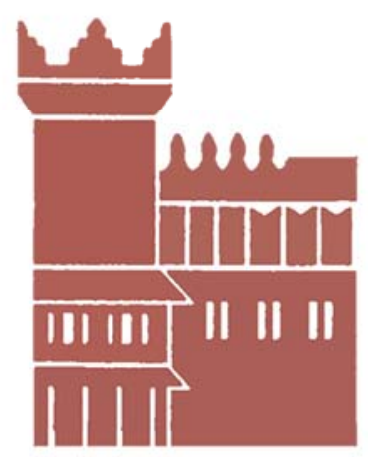

Alma Mater Studiorum - Università di Bologna DEPARTMENT OF ECONOMICS

Strada Maggiore 45

40125 Bologna - Italy

Tel. +39051 2092604

Fax +390512092664

http://www.dse.unibo.it 